\title{
POSSIBILIDADES DE SOFRIMENTO PSÍQUICO DO PROFESSOR UNIVERSITÁRIO DE UMA LICENCIATURA
}

\author{
Kelly Cristina Tesche Rozendo ${ }^{1}$, Carmen Lúcia Dias ${ }^{2}$ \\ ${ }^{1}$ Universidade do Oeste Paulista - UNOESTE. ${ }^{1}$ Curso de Psicologia, ${ }^{2}$ Mestrado em Educação, Presidente Prudente - SP. \\ Agência Financiadora: Pibic/CNPq. E-mail: kellytesche@hotmail.com
}

\begin{abstract}
RESUMO
O trabalho docente tem revelado processos de adoecimento no âmbito laboral. Pensando nisso, esta pesquisa teve como objetivo geral analisar o sofrimento psíquico de professores universitários das licenciaturas, buscando destacar aspectos que compõem seu ambiente de trabalho. Especificamente, verificou-se a concepção que professores do curso de licenciatura em Pedagogia têm sobre a docência; identificou-se características do ambiente de trabalho dos professores universitários; investigou-se a saúde física e mental destes profissionais. Com abordagem qualitativa, do tipo estudo de caso, a metodologia envolveu a coleta de dados, por meio de questionário e entrevista semiestruturados com quatorze professores do curso de licenciatura em Pedagogia de uma Instituição de Ensino Superior particular do estado de São Paulo. A análise organizou-se por eixos e categorias. Os resultados revelaram que aspectos do ambiente laboral acadêmico podem repercutir em sofrimento psíquico e produzir efeitos negativos na saúde dos professores universitários.
\end{abstract}

Palavras-chave: Sofrimento Psíquico; Trabalho; Professor Universitário; Pedagogia.

\section{POSSIBILITIES OF PSYCHIC SUFFERING OF UNIVERSITY PROFESSOR OF UNDERGRADUATE}

\begin{abstract}
Teaching work has revealed cases of illness in the workplace. Thinking about it, this research has the general objective to analyze the psychic suffering of university professor of undergraduate, seeking to highlight aspects that make your work environment. Specifically, was checked the conception that Pedagogy undergraduate professors have about teaching; was identified characteristics of the working environment of university professors; was investigated the physical and mental health of these professionals. Using a qualitative approach and case study type, the methodology involved the collection of data, through a questionnaire and interviews semistructured with fourteen professors of the undergraduate in Pedagogy course of a particular Higher Education Institution in the state of São Paulo. The analysis was organized by axes and categories. The results revealed that aspects of the academic work environment may impact on psychic suffering and adversely affecting the health of the university professors.
\end{abstract}

Keywords: Psychic Suffering; Work; University Professor; Pedagogy.

\section{INTRODUÇÃO}


O ambiente laboral pode desencadear queixas de comprometimento na saúde dos trabalhadores por condições laborais precárias que levam ao desgaste mental e repercutem negativamente em todos os âmbitos da vida. Por sua vez, o trabalho contemporâneo nas universidades pode funcionar como fonte de exaustão e adoecimento, desestabilizando e colocando em risco a saúde física e psíquica dos trabalhadores. No entanto, o contexto acadêmico propriamente dito não possui literatura vasta referente a esta temática.

Lima e Lima-Filho (2009) afirmam que investigações sobre a dinâmica de produção do desgaste mental no âmbito do trabalho podem viabilizar prevenções para diminuição da carga psíquica. Para Araújo et al. (2005) aprofundar estes estudos permite analisar os processos laborais e descrever o perfil de adoecimento dos trabalhadores $\mathrm{e}$ as associações entre o trabalho e a saúde. Logo, na tentativa de cooperar para ampliação destes conhecimentos, este estudo, revestido de preocupações e indagações apoiadas na proposição central de que o trabalho dos professores universitários pode desencadear sofrimento psíquico nesses profissionais, apresentou como referencial teórico contribuições da Psicodinâmica do Trabalho e da Psicologia Social, além de artigos científicos coletados nas principais bases de dados brasileiras.
A Psicodinâmica do Trabalho tem como suporte o conhecimento e a descrição das relações entre trabalho e saúde mental, podendo contribuir para a análise das relações entre trabalho e subjetividade. De acordo com Dejours (2004, p. 30) "Trabalhar não é somente produzir; é, também, transformar a si mesmo e, no melhor dos casos, é uma ocasião oferecida à subjetividade para se testar, até mesmo para se realizar". Essa corrente considera o trabalho no âmbito objetivo e subjetivo. A carga laboral divide-se em carga física e psíquica, englobando visões singulares de cada ser humano de vivenciar o trabalho, cujo fator se relaciona com desgaste mental e pode produzir insatisfação, irritação, exaustão, sofrimento e adoecimento (DEJOURS, 1991; 2004).

Na Psicologia Social, Codo (1999, p. 31) afirma que "Ser Humano significa ser Histórico". O que faz o homem ser histórico é a possibilidade de permanecer apesar de si, e isso ocorre através do trabalho, no qual os gestos são imortalizados. Segundo Codo, Sampaio e Hitomi (1993) o trabalho é parte da história dos seres humanos. Para Codo e Sampaio (1995, p.209) "o trabalho é o modo de ser do Homem, como tal invade e se permeia com todos os níveis de sua atividade, seus afetos, sua consciência". Nesta perspectiva, o trabalho, principal atividade humana, produz efeitos sob o 
trabalhador, determinando o processo de saúde e de doença mental nos indivíduos.

À luz destas teorias, o trabalho é destacado como fator de importância capital na produção de sofrimento psíquico e de adoecimento nos trabalhadores. A partir disto, investigações indicam que o trabalho de docência se destaca ao evidenciar sofrimento psíquico em seu âmbito laboral (MENDES et al., 2007; VEDOVATO; MONTEIRO, 2008; GARCIA; OLIVEIRA; BARROS, 2008; RIBEIRO; MARTINS, 2011).

Decerto o cotidiano e a situação laboral das instituições acadêmicas possuem elementos que podem desencadear problemas de ordem psíquica e potencializar vivências depressivas nos professores universitários. Servilha e Arbach (2011) relatam que na especificidade das tarefas desses profissionais encontram-se contidos fatores de risco capazes de promover sofrimento psíquico e influenciar a saúde dos docentes. Entre esses fatores, Gradella (2010) destaca o compromisso com a formação dos sujeitos humanos de maneira contínua. Garcia, Oliveira e Barros (2008) enfatizam as responsabilidades além desse compromisso, pois os professores devem preocupar-se inclusive com a própria formação. Destaca-se ainda, conforme Codo (1999), o conteúdo afetivo submerso na atividade docente como fator de sofrimento psíquico.
Cabe salientar ainda que o ambiente educacional e sua configuração nas últimas décadas sofreram uma intensa transformação que alterou sua condição e organização laboral. Trata-se do movimento de globalização e reestruturação capitalista, o qual promoveu intensas reformas que influenciam na estruturação e valorização social da atividade docente. Essas transformações favorecem um significativo quadro de desgaste biopsíquico nos profissionais da educação, podendo afetar a saúde física e psíquica desses trabalhadores (ARAÚJO et al., 2005; GUIMARÃES; MARTINS, 2010; XAVIER, 2011; JILOU, 2013).

Nesta mesma linha, Gradella (2010) afirma que o processo de sofrimento psíquico decorre das relações de dominação e desumanização impostas pelo capitalismo, o qual se encontra no centro da organização do mundo, influenciando um processo de alienação que não possibilita objetivação e realização do trabalhador na atividade que exerce. Dejours (2004) aponta que o trabalho não é somente uma atividade, senão uma forma de relação que se desdobra em um mundo caracterizado por relações de desigualdade, de poder e de dominação. Por certo, a lógica de produção influencia nessas relações podendo gerar vias dolorosas e, segundo Gradella (2010), causar desajustes no plano psicológico e sofrimento psíquico aos trabalhadores. 
Esse sofrimento refere-se a uma descompensação que se origina na organização do trabalho produzindo angústias, desgostos, ansiedades, frustrações e infelicidade. Para Codo (1999, p. 311) “O fator nocivo do trabalho não está na dedicação, no empenho, mas nas condições, na organização e na relação com o trabalho". Dejours (1991, 2004) indica que a organização laboral pode promover um agravamento das patologias mentais.

Apesar destes desgastes mentais, Dejours (1991) explica que no trabalho o sofrimento precisa ser mantido de maneira invisível, para que se mantenha o ritmo laboral e um suposto equilíbrio mental. $\mathrm{Na}$ organização do trabalho apenas o sofrimento físico é reconhecido, desconsiderando a possibilidade de que doenças somáticas podem ser desencadeadas pelo sofrimento psíquico.

A expectativa ao realizar este estudo foi oferecer elementos de base e orientação, que contribuam para deflagrar um processo de reflexão a respeito do relevante papel e da ação dos profissionais da educação perante a sociedade, bem como da relação do trabalho com o sofrimento psíquico e com a saúde física e mental desses trabalhadores. Para tanto, esta pesquisa delineou como objetivo geral analisar o sofrimento psíquico dos professores universitários de uma licenciatura, buscando destacar aspectos e características que compõem seu ambiente de trabalho. Como objetivos específicos, pretendeu-se verificar a concepção que os professores do curso de licenciatura em Pedagogia têm sobre o exercício da docência; identificar os aspectos que compõem o ambiente de trabalho dos professores universitários; e investigar a saúde física e mental destes profissionais.

\section{METODOLOGIA}

Com o objetivo de analisar as possibilidades de sofrimento psíquico dos professores universitários das licenciaturas, esta pesquisa, inscrita na Coordenadoria Central de Pesquisa (CCPq/UNOESTE) sob protocolo número 1601, agência financiadora PIBIC/CNPq, foi realizada segundo a abordagem qualitativa, do tipo estudo de caso. A coleta de dados foi realizada por meio de questionário e entrevista semiestruturados com quatorze professores que ministram aulas em um curso de licenciatura em Pedagogia de uma Instituição de Ensino Superior (IES) particular do estado de São Paulo. O critério de escolha dos participantes foi por sorteio, ou seja, $60 \%$ do total de professores do referido curso, garantindo a representatividade, a não identificação e o sigilo dos sujeitos.

Após aprovação do Comitê de Ética em Pesquisa e assinatura do Termo de Consentimento Livre Esclarecido (TCLE) pelos 
sujeitos, os questionários foram entregues e deixados em posse dos professores, em função da comodidade para o preenchimento do mesmo. Todos os sujeitos sorteados receberam o questionário proposto pela pesquisa, porém três deles não devolveram e não contestaram a qualquer tipo de tentativa de contato para recolhimento do material. Logo, a fim de enriquecer e aprofundar o estudo, foram sorteados três sujeitos para realização de entrevistas, para efeito de compreensão e assimilação do sentido das perguntas propostas. Durante as entrevistas, tal como proposto por Oliveira (2008), o entrevistador limitou-se a ouvir e não interferiu nas respostas dos entrevistados.

Os dados obtidos foram analisados e trabalhados por meio da análise de conteúdo apresentada por Bardin (2011), que consiste na interpretação do significado das respostas (escrita ou oral). As diferentes fases da análise se organizaram em torno de polos cronológicos, a saber, pré-análise, exploração do material, tratamento dos resultados, inferência e interpretação. Os dados foram organizados por eixos e categorias, as quais, podendo ser agrupadas de acordo com afinidades temáticas para a discussão, foram relacionadas com os objetivos propostos por esta pesquisa.

\section{RESULTADOS}

Os participantes desta pesquisa foram denominados Sujeitos 1, 2, 3, 4, 5, 6, 7, 8, 9, $10,11,12,13,14$, cujos dados pessoais e profissionais encontram-se dispostos na Tabela 1 e na Tabela 2. 
Tabela 1. Identificação do Perfil Docente (Dados Pessoais)

\begin{tabular}{|c|c|c|c|c|}
\hline & Sexo & Idade & Estado Civil & Residência \\
\hline Sujeito 1 & Feminino & 55 & Casada & Pres. Prudente/SP \\
\hline Sujeito 2 & Feminino & 40 & Divorciada & Pres. Prudente/SP \\
\hline Sujeito 3 & Masculino & 38 & Solteiro & Pres. Prudente/SP \\
\hline Sujeito 4 & Masculino & 56 & Solteiro & Pres. Prudente/SP \\
\hline Sujeito 5 & Feminino & 47 & Casada & Pres. Prudente/SP \\
\hline Sujeito 6 & Feminino & 53 & Casada & Pres. Prudente/SP \\
\hline Sujeito 7 & Feminino & 49 & Casada & Pres. Prudente/SP \\
\hline Sujeito 8 & Masculino & 52 & Solteiro & Pres. Prudente/SP \\
\hline Sujeito 9 & Feminino & 69 & Divorciada & Pres. Prudente/SP \\
\hline Sujeito 10 & Feminino & 53 & Casada & Pres. Prudente/SP \\
\hline Sujeito 11 & Masculino & 53 & Casado & Pres. Prudente/SP \\
\hline Sujeito 12 & Masculino & 46 & Solteiro & Pres. Prudente/SP \\
\hline Sujeito 13 & Feminino & 69 & Viúva & Pres. Prudente/SP \\
\hline Sujeito 14 & Feminino & 54 & Separada & Pres. Prudente/SP \\
\hline
\end{tabular}

Fonte: Dados trabalhados pelo pesquisador.

A Tabela 1 traz informações sobre os dados pessoais de identificação do perfil docente e permite entender que a idade dos participantes variou de 38 a 69 anos, sendo cinco masculinos e nove femininos. Destes, sete são casados, três solteiros, dois divorciados, um separado e um viúvo. Todos residem na cidade de Presidente Prudente no estado de São Paulo.

A seguir apresenta-se a Tabela 2, cujas informações se referem aos dados profissionais de identificação do perfil docente. 
Tabela 2. Identificação do Perfil Docente (Dados Profissionais)

\begin{tabular}{|c|c|c|c|c|c|c|}
\hline & $\begin{array}{l}\text { Formação } \\
\text { Acadêmica }\end{array}$ & $\begin{array}{l}\text { Tempo de } \\
\text { Docência }\end{array}$ & $\begin{array}{l}\text { Contrato com a } \\
\text { Instituição de } \\
\text { Ensino Superior - } \\
\text { IES }\end{array}$ & $\begin{array}{l}\text { Disciplina que } \\
\text { ministra }\end{array}$ & $\begin{array}{l}\text { Exerce a } \\
\text { docência em } \\
\text { outra } \\
\text { instituição }\end{array}$ & $\begin{array}{l}\text { Exerce outra } \\
\text { atividade } \\
\text { laboral }\end{array}$ \\
\hline Sujeito 1 & $\begin{array}{l}\text { Especialista } \\
\text { Mestre }\end{array}$ & 16 anos & Integral & $\begin{array}{l}\text { História da } \\
\text { Educação; } \\
\text { Didática; } \\
\text { Avaliação } \\
\text { Educacional }\end{array}$ & Não & Não \\
\hline Sujeito 2 & $\begin{array}{l}\text { Doutora em } \\
\text { Psicologia }\end{array}$ & 7 anos & Parcial & $\begin{array}{l}\text { Psicologia da } \\
\text { Educação }\end{array}$ & $\begin{array}{l}\text { Sim, em } \\
\text { Universidad } \\
\text { e Pública }\end{array}$ & Sim \\
\hline Sujeito 3 & $\begin{array}{l}\text { Mestre em } \\
\text { Filosofia }\end{array}$ & 8 anos & Parcial & $\begin{array}{l}\text { Filosofia; } \\
\text { História (Arte) } \\
\end{array}$ & Não & Não \\
\hline Sujeito 4 & Mestre & 30 anos & Parcial & Não citado & Não & Não \\
\hline Sujeito 5 & $\begin{array}{l}\text { Especialista em } \\
\text { Gestão } \\
\text { Educacional; } \\
\text { Mestre em } \\
\text { Educação }\end{array}$ & 11 anos & Parcial & $\begin{array}{l}\text { Fundamentos e } \\
\text { diretrizes da } \\
\text { Educação } \\
\text { infantil; } \\
\text { Organização } \\
\text { pedagógica. }\end{array}$ & Não & Sim \\
\hline Sujeito 6 & $\begin{array}{l}\text { Mestre em } \\
\text { Educação }\end{array}$ & 1 ano & Parcial & $\begin{array}{l}\text { Letramento e } \\
\text { alfabetização;M } \\
\text { etodologia do } \\
\text { ensino de } \\
\text { Matemática. }\end{array}$ & $\begin{array}{l}\text { Sim, no } \\
\text { Ensino } \\
\text { Fundamental }\end{array}$ & Não \\
\hline Sujeito 7 & Mestre & 6 anos & Parcial & Não citado & Não & Não \\
\hline Sujeito 8 & $\begin{array}{l}\text { Mestre em } \\
\text { Educação }\end{array}$ & 21 anos & Integral & $\begin{array}{l}\text { Ciências Sociais; } \\
\text { Filosofia; } \\
\text { Sociologia; } \\
\text { Geografia. } \\
\end{array}$ & $\begin{array}{l}\text { Sim, na } \\
\text { Educação } \\
\text { Básica }\end{array}$ & Sim \\
\hline Sujeito 9 & Mestre & 26 anos & Parcial & Não citado & Não & Não \\
\hline Sujeito 10 & Doutora & 13 anos & Integral & Não citado & Não & Sim \\
\hline Sujeito 11 & $\begin{array}{l}\text { Especialista em } \\
\text { Ciências } \\
\text { Humanas e } \\
\text { Sociais; } \\
\text { Mestre em } \\
\text { Educação }\end{array}$ & 28 anos & Integral & Não citado & Não & Não \\
\hline Sujeito 12 & Especialista & 12 anos & Parcial & Não citado & Não & Não \\
\hline Sujeito 13 & $\begin{array}{l}\text { Mestre em } \\
\text { Educação }\end{array}$ & 30 anos & Parcial & Não citado & Não & Não \\
\hline Sujeito 14 & $\begin{array}{l}\text { Doutora em } \\
\text { Educação }\end{array}$ & 16 anos & Parcial & Não citado & $\begin{array}{l}\text { Sim, no } \\
\text { Ensino } \\
\text { Médio }\end{array}$ & Sim \\
\hline
\end{tabular}

Fonte: Dados trabalhados pelo pesquisador.

As informações da Tabela 2 indicam que todos os sujeitos possuem graduação, sendo três doutores, três especialistas e mestres, sete mestres e um especialista. O tempo de docência no ensino superior variou de um a trinta anos. Quatro participantes 
possuem contrato integral com a IES e dez possuem contrato parcial. O número de horas destes contratos varia de quarenta e oito a dez horas de trabalho. Alguns participantes exercem a docência em outras instituições. O Sujeito 2 atua em outra IES. Os Sujeitos 6 e 8 exercem a docência na Educação Básica e o Sujeito 14 no Ensino Médio. Os demais participantes não exercem a docência em outras instituições, porém os Sujeitos 2, 5, 8, 10 e 14 atuam em outras atividades laborais. Entre as aulas que os participantes ministram encontram-se disciplinas referentes à: História da
Educação; Didática; Avaliação Educacional; Psicologia da Educação; Filosofia; História da Arte; Fundamentos e Diretrizes da Educação Infantil; Organização do Trabalho Pedagógico; Letramento e Alfabetização; Metodologia do Ensino de Matemática; Ciências Sociais; Sociologia; Geografia. Alguns sujeitos não citaram as disciplinas cujos conteúdos lecionam aulas.

A seguir, a Tabela 3 apresenta eixos e categorias, os quais foram organizados com base no roteiro do questionário/entrevista aplicados aos participantes da pesquisa.

TABELA 3. Eixos e Categorias

\begin{tabular}{|c|c|}
\hline EIXOS & CATEGORIAS \\
\hline \multirow{7}{*}{$\begin{array}{l}\text { I- Concepção sobre o } \\
\text { exercício de docência }\end{array}$} & 1 Concepção sobre docência (Q1) \\
\hline & 2 Inserção na carreira docente (Q2) \\
\hline & 3 Importância da docência para vida do professor (Q3) \\
\hline & 4 Requisitos necessários para o exercício da docência (Q4) \\
\hline & 5 Interesse em trabalhar com a Educação Superior (Q5) \\
\hline & 6 Requisitos necessários para trabalhar com universitários (Q 6) \\
\hline & 7 Importância dos professores universitários para a sociedade (Q7) \\
\hline \multirow{14}{*}{$\begin{array}{l}\text { II - Ambiente de trabalho } \\
\text { na universidade }\end{array}$} & 1 Impacto das leis de mercado nas universidades e na profissão (Q1) \\
\hline & 2 Influências dos avanços tecnológicos na atuação profissional (Q2) \\
\hline & 3 Ambiente de trabalho (Q3) \\
\hline & 4 Condições e organização laboral (Q4) \\
\hline & 5 Liberdade e autonomia no trabalho (Q5) \\
\hline & 6 Sobrecarga laboral (Q6) \\
\hline & 7 Competição laboral (Q7) \\
\hline & 8 Remuneração da profissão (Q8) \\
\hline & 9 Reconhecimento do trabalho (Q9) \\
\hline & 10 Satisfação laboral (Q10) \\
\hline & 11 Pontos favoráveis e desfavoráveis da docência (Q11) \\
\hline & 12 Mudanças no ambiente laboral (Q12) \\
\hline & 1 Relação trabalho/saúde (Q1) \\
\hline & 2 Problemas de saúde após ingressar na docência (Q2) \\
\hline
\end{tabular}




\begin{tabular}{l|l}
\hline \multirow{4}{*}{$\begin{array}{l}\text { III - Saúde física e mental } \\
\text { do professor universitário }\end{array}$} & 3 Sintomas físicos ou mentais e saúde (Q3) \\
\cline { 2 - 2 } & 4 Episódios de fadiga física e/ou mental (Q4) \\
\cline { 2 - 2 } & 7 Anseios e aspirações no trabalho e na vida privada (Q5) \\
\cline { 2 - 2 } & 8 Relações sociais no trabalho (Q8) \\
\cline { 2 - 2 } & 9 Situações de lazer (Q9) \\
\cline { 2 - 2 } & 10 Separação da vida profissional e privada (Q10) \\
\cline { 2 - 2 } & 11 Trabalhos da IES realizados em casa (Q11) \\
\cline { 2 - 2 } & 12 Ingestão de bebidas alcoólicas e tabaco (Q12) \\
\hline & 13 Prática de esportes (Q13) \\
\cline { 2 - 2 } & 14 Tempo de lazer (Q14) \\
\cline { 2 - 2 } & 15 Relação da docência com o sofrimento psíquico (Q15) \\
\cline { 2 - 2 } & 16 Motivações e desmotivações no exercício da docência (Q16) \\
\hline
\end{tabular}

Fonte: Dados trabalhados pelo pesquisador.

A Tabela 3 indica que o Eixo $I$, concepção sobre o exercício de docência, verificou por meio de categorias aspectos relacionados à concepção sobre docência; inserção na carreira docente; importância da docência para vida do professor; requisitos necessários para o exercício da docência; interesse em trabalhar com a educação superior; requisitos necessários para trabalhar com universitários; importância dos professores universitários para a sociedade. O Eixo II, ambiente de trabalho na universidade, investigou mediante categorias o impacto das leis de mercado nas universidades e na profissão; influências dos avanços tecnológicos na atuação profissional; ambiente de trabalho; condições e organização laboral; liberdade e autonomia no trabalho; sobrecarga laboral; competição laboral; remuneração da profissão; reconhecimento do trabalho; satisfação laboral; pontos favoráveis e desfavoráveis da docência; mudanças no ambiente laboral. O Eixo III, saúde física e mental do professor universitário, verificou a relação trabalho/saúde; problemas de saúde após ingressar na docência; sintomas físicos ou mentais e saúde; episódios de fadiga física e/ou mental; anseios e aspirações no trabalho e na vida privada; gostar do que faz; prazer e desprazer no trabalho; relações sociais no trabalho; situações de lazer; separação da vida profissional e privada; trabalhos da IES realizados em casa; ingestão de bebidas alcoólicas e tabaco; prática de esportes; tempo de lazer; relação da docência com o sofrimento psíquico; motivações e desmotivações no exercício da docência. 


\section{DISCUSSÃO}

No Eixo I - Concepção sobre o exercício de docência - é importante frisar que para Codo (1999, p. 418) a docência "é um trabalho completo, artesanal, desses que são raros em mundo de hoje." Na categoria 1, concepção sobre docência, os Sujeitos 3, 5, 7,8 e 14 descrevem que ser professor consiste numa troca, num compartilhamento, compreendendo a docência como um processo mútuo capaz de mobilizar transformações e construções. Nas palavras do Sujeito 7 ser professor é construir o conhecimento com o aluno. Tal posicionamento remete a Masetto (2003) e a Freire (2011), cujas visões apontam os professores do ensino superior como parceiros que compartilham e aprendem saberes com os outros. Esse processo de transmissão e aquisição de conhecimentos foi mencionado na categoria 2, inserção na carreira docente, como um dos fatores motivacionais para $o$ ingresso dos participantes desta pesquisa na profissão de docência.

As categorias 3 e 7 se referem a importância da docência para a vida do professor e a importância dos professores universitários para a sociedade. Tais categorias instigaram os sujeitos a refletirem sobre sua prática. A partir desta reflexão, o valor da docência adquiriu entonações afetivas e práticas, no sentido de que para os participantes a profissão além de permitir o processo de ensino e aprendizagem e de contribuir para a formação dos cidadãos sociais e de outros professores, possibilita a manifestação do amor e o desenvolvimento de vínculos significativos. Codo (1999) alerta que há uma tensão entre vincular-se e não vincular-se afetivamente no trabalho docente. Conforme a intensidade dessa tensão pode instaurar-se um quadro de sofrimento nos professores.

As categorias 4, 5 e 6 correspondem aos requisitos necessários para o exercício da docência e para trabalhar com universitários e, ao interesse em trabalhar com a educação superior. Percebe-se que diferentes fatores levaram os professores desta pesquisa a atuarem na docência superior, entre eles, as oportunidades de empregos e a vontade de contribuir para a formação de novos professores. Para os Sujeitos 2, 3, 4, 5, 6, 8, 10, 11, 12, 13 e 14 a docência exige persistência, competência, paciência e principalmente, conhecimento teórico e técnico, formação adequada e boa relação professor/aluno. Tardif (2010) salienta que o saber docente se define pela formação mais ou menos coerente de conhecimentos oriundos da formação profissional e dos saberes disciplinares, curriculares e experienciais. Para Tardif (2010, p. 130) os professores devem "fazer com que as ações 
dos alunos se harmonizem com as suas, ao invés de se oporem a elas."

No Eixo II - Ambiente de trabalho na universidade - deve-se considerar que $\mathrm{o}$ sistema capitalista instalou um novo modelo de configuração nas universidades, remetendo-as às novas leis de mercado e promovendo deterioramento e precarização nas condições laborais (LIMA; LIMA-FILHO, 2009; GRADELLA, 2010). As categorias 1 e 2 ao se referirem ao impacto das leis de mercado nas universidades e na profissão de docência e às influências dos avanços tecnológicos na atuação profissional, revelam exigências de profissionais cada vez mais competentes e com habilidades múltiplas. Além disso, os sujeitos desta pesquisa salientam que as novas leis de mercado são instáveis, apresentam interesse elevado pelo lucro e oferecem infraestrutura precária e desvalorização. Para Jilou (2013) o contexto laboral dos professores universitários encontra-se revestido com instabilidade, ameaças, precarização, valorização excessiva do capital e desvalorização da imagem docente.

As categorias 3 e 4 , se referem ao ambiente de trabalho e as condições e organização laboral, englobando aspectos referentes aos recursos dispostos no contexto e na organização do trabalho na universidade. Neste sentido, a maioria da amostra afirma que o ambiente humano na
IES em questão, em geral é agradável, prazeroso, bom e gratificante. Porém, os recursos físicos e materiais oferecidos são escassos e as salas não são preparadas para acolher a atividade docente, o que gera sobrecarga laboral. Segundo os participantes a falta de equipamentos didáticos instalados nas salas de aula faz com que os professores tenham que carregar peso em demasia, preparar e instalar aparelhos quando necessários, bem como, exige deslocamentos constantes. Tais situações vão de encontro com estudos de Araújo et al. (2005), nos quais são apontadas as mesmas deficiências no ambiente laboral dos professores universitários. Dejours (2004) afirma que a pior organização laboral se caracteriza, entre outros fatores, por infraestrutura precária e pela falta de conforto oferecido pelas instituições.

As categorias 5 e 10 referem-se à liberdade e autonomia no trabalho e à satisfação laboral. Gradella (2010), Xavier (2011) e Suda et al. (2011) ressaltam que entre os fatores desencadeantes dos problemas de ordem psíquica encontram-se a falta de autonomia, de liberdade e as cobranças psicológicas no mundo do trabalho. Por sua vez, os Sujeitos 1, 3, 4, 5, 7, 9, 10,11 e 13 consideram o trabalho satisfatório e afirmam que possuem liberdade e autonomia para desempenhar suas funções na IES, porém demonstram 
certas insatisfações com relação a diversos aspectos. Nas palavras do Sujeito 2 na universidade não há tanta liberdade, os prazos são rígidos [...] o trabalho é cerceado e há conflitos. Quiçá decorrente disto, o Sujeito 12 não sente satisfação em seu trabalho. Para Codo (1999) e Mendes et al. (2007) quando os professores universitários não obtêm satisfação e são afetados pela organização do trabalho colocam em risco seu equilibro psíquico e sua saúde mental.

Nas categorias 6 e 7 - sobrecarga laboral; competição laboral - cabe salientar que alguns aspectos do mundo do trabalho acadêmico promovem sensações de esvaziamento e descontentamento, entre eles, as intensificações do ritmo de trabalho e a competição acirrada (GRADELLA, 2010; SUDA et al., 2011; XAVIER, 2011). Corroborando, os Sujeitos 2, 3, 5, 8 e 14 garantem que há sobrecarga laboral na universidade. Em contrapartida, a competição laboral é tida por alguns participantes como inexistente no mundo do trabalho acadêmico, sendo este o posicionamento dos Sujeitos 1, 3, 4, 9 e 10, os quais confrontam inúmeros autores que embasam esta pesquisa, uma vez que a competição acirrada é considerada fator inerente ao contexto da universidade (LIMA; LIMA-FILHO, 2009; GRADELLA, 2010). Para legitimar tais perspectivas, tornam-se relevantes os depoimentos dos Sujeitos 2, 5,
$6,7,8,12$ e 13 , para os quais sempre há competição no ambiente laboral docente.

Nas categorias 8 e 9 apresentam-se temáticas referentes a remuneração da profissão docente e ao reconhecimento do trabalho. Segundo Codo (1999) ser professor deixou de ser compensador, pelos salários baixos, pela falta de status social e pela falta de reconhecimento dos profissionais da educação. A maioria dos participantes desta pesquisa concorda que a docência não possui remuneração adequada. Apesar disto, os Sujeitos 1, 4, 6, 7, 8, 9, 10, 11, 13 e 14 sentem que seu trabalho é reconhecido pela IES em questão. De acordo com Codo (1999) o reconhecimento e a valorização dão sentido ao trabalho. Para Guimarães e Martins (2010) a falta de reconhecimento laboral ameaça a integridade dos professores, determinando o sofrimento psíquico.

As categorias 11 e 12 se referem aos pontos favoráveis e desfavoráveis da docência e as mudanças no ambiente laboral. Dejours (2004) revela que o trabalho pode corresponder a um processo negativo ou positivo, ou seja, pode apresentar aspectos favoráveis e desfavoráveis. Diante dos fatores negativos, Mendes et al. (2007) afirmam que os professores se deparam com a incapacidade de mudança. Para Codo (1999) esta incapacidade se associa ao desânimo e as sensações de derrota nos professores. 
Entre os pontos favoráveis da profissão de docência os professores universitários apontaram a contribuição para a educação, o conhecimento e as relações interpessoais que se entrelaçam em sala de aula. Os fatores adversos foram relacionados à falta de reconhecimento e remuneração adequada, estresse, trabalho excessivo, cansaço e conflitos. Para Lima e Lima-Filho (2009) e Xavier (2011) entraves do ambiente laboral dos docentes permitem vivências de conflitos intensos, desvalorização e sobrecarga laboral. Estes fatores negativos representam os desejos de mudanças dos professores universitários quanto às condições de trabalho que permeiam a universidade.

No Eixo III - Saúde física e mental do professor universitário - buscou-se verificar por meio de categorias aspectos relacionados à relação do trabalho com a saúde. As categorias 1,2 e 15 se referem à relação trabalho/saúde, aos problemas de saúde após ingressar na docência e a relação da docência com o sofrimento psíquico. Estas categorias foram vinculadas para a análise e interpretação dos dados.

Segundo Araújo et al. (2005) e Gradella (2010) os professores universitários evidenciam enfermidades após o ingresso na carreira acadêmica. Na presente pesquisa, grande parte da amostra considera que $o$ trabalho possui relação com a saúde, sendo que os Sujeitos 5, 6 e 14 relataram sintomas de cansaço físico, desgaste na voz, inquietação e nervosismo após o ingresso na carreira acadêmica. Além disso, os sujeitos afirmam que a profissão de docência pode fazer emergir sofrimento psíquico. Opiniões estas que corroboram Codo (1999) e Gradella (2010), os quais descrevem uma tendência para que o trabalho docente desencadeie sofrimento psíquico e, em casos extremos, psicopatologias. As queixas e os efeitos do ambiente organizacional do trabalho refletem negativamente nas esferas física, psíquica e social (ARAÚJO et al., 2005; MENDES et al., 2007; GRADELLA, 2010; RIBEIRO; MARTINS, 2011; IWATA et al., 2011).

As categorias 3 e 4 buscaram informações a respeito dos sintomas físicos ou mentais dos professores universitários e investigaram episódios de fadiga física e/ou mental nestes profissionais. A despeito disto, os Sujeitos 2, 4, 5, 6, 7, 8, 11, 12 e 14 descrevem episódios de estresse, cansaço excessivo, dor de cabeça, queimação estomacal, ansiedade e depressão. Jilou (2013) constatou que o sofrimento dos professores universitários esta relacionado à ansiedade, estresse, cansaço, frustração, desconforto, entre outras queixas que levam os profissionais da educação a quadros enfermos. Enfermidades crônicas como hipertensão, distúrbios gastrointestinais, 
depressão, mialgias e infarto agudo do miocárdio são acarretadas pela omissão do sofrimento do trabalhador. Codo (1999) alerta que o indivíduo que sofre pode não se dar conta por tratar-se de um sofrimento que se passa a nível psicológico. Ao ignorar o problema, podem surgir diferentes tipos de dores, perda da voz, cansaço, irritabilidade, entre outras dificuldades que amiúde acometem os trabalhadores.

A categoria 5 - anseios e aspirações no trabalho e na vida privada - buscou investigar se o trabalho dos docentes na educação superior corresponde aos desejos particulares de cada profissional. De acordo com Dejours, Dessors e Desriaux (1993) os trabalhadores possuem histórias individuais que envolvem aspirações, motivações e necessidades psicológicas. No trabalho, ocorre um embate entre essa história e a realidade externa que promove sofrimento psíquico (DEJOURS, 1991; CODO; SAMPAIO; HITOMI, 1993; LIMA; LIMA-FILHO, 2009). Neste sentido, os Sujeitos 1, 4, 6, 9, 10, 12 e 13 garantem que seus desejos e anseios correspondem à atividade laboral realizada na universidade. Já os Sujeitos 2, 3, 5, 7 e 8 revelam que não há coincidência entre o trabalho e seus desejos pessoais. Para Mendes et al. (2007) e Ribeiro e Martins (2011) o trabalho que não coincide com o ritmo biológico e psicoafetivo do trabalhador pode gerar sofrimento psíquico e prejudicar a saúde física e mental.

As categorias 6, 7 e 16 dizem respeito a gostar do que faz, prazer e desprazer no trabalho e motivações e desmotivações no exercício da docência. Guimarães e Martins (2010) indicam que os valores relativos ao trabalho e variáveis do ambiente laboral podem contribuir para a predição do prazer e do sofrimento no âmbito do trabalho acadêmico, podendo servir de motivações ou desmotivações para os profissionais. $\mathrm{Na}$ presente pesquisa, todos os participantes garantem gostar da profissão que exercem, apesar de citarem inúmeras insatisfações.

Com relação ao prazer e às motivações no trabalho foram apontados vários fatores, entre eles, a interrelação e o interesse dos alunos, o amor, a liberdade para organizar o trabalho, a remuneração adequada, o reconhecimento merecido, o processo de ensino e aprendizagem e a contribuição para a formação da sociedade. Porém, estes fatores tidos pelos sujeitos como impulsionadores do exercício da docência, por vezes não se encontram presentes no trabalho desta categoria. Dentre os aspectos relacionados ao desprazer e às desmotivações foram mencionados o desinteresse dos alunos, a correção de provas, a remuneração inadequada, o estresse, o trabalho excessivo e a burocracia. Mendes et al. (2007) afirmam 
que o quadro de sofrimento psíquico dos professores universitários é potencializado por angústias e insatisfações na instituição e por aspectos relacionados a convivência com os alunos, relações sociais, sobrecarga laboral, burocracia e alienação.

A categoria 8 aborda aspectos concernentes as relações sociais no trabalho. Para Guimarães e Martins (2010) o trabalho é um importante fator de inserção social que implica fatores psíquicos e físicos. $\mathrm{Na}$ presente pesquisa, as relações sociais com os colegas de trabalho e com os alunos foram descritas por todos os participantes, como boas, munidas de cordialidades, respeito e integração, revelando um clima agradável e amistoso na universidade, entretanto estas relações são distantes. A título de exemplo, os Sujeitos 5, 7 e 8 declaram que a relação com os colegas de trabalho não ultrapassa os corredores e acontecem somente dentro do limite de trabalho. De acordo com Codo (1999, p. 296) "cerca de $18 \%$ dos profissionais em educação reclamam da falta de suporte social nas suas vidas". A falta deste suporte leva a uma fragilidade emocional e provoca sofrimento intenso, pois o apoio social é importante para o bem-estar emocional e para a manutenção da saúde mental no trabalho.

As categorias 10 e 11 referem-se à separação da vida profissional e privada e a trabalhos da IES realizados em casa. Para
Iwata et al. (2011) vincular-se as relações de trabalho de forma ilimitada prejudica a saúde psíquica dos profissionais. Não obstante, os Sujeitos 1, 3, 4, 5, 7, 8, 9, 10,11, 12 e 13 afirmam que conseguem separar a vida profissional da vida privada, no entanto todos os participantes assumem que levam trabalhos da instituição para fazer em casa. 0 Sujeito 8 afirma [...] sempre ocorre uma extensão do ambiente de trabalho ao ambiente doméstico. Para Codo (1999) o trabalho do educador requer dedicação as atividades e exigências que vão além da sala de aula. Ao estender o trabalho para o ambiente pessoal, este profissional derruba as barreiras entre o mundo pessoal e o profissional, que deveriam permanecer para a diminuição da carga psíquica e para preservação da saúde dos trabalhadores (CODO, 1999; ARAÚJO et al., 2005; GARCIA; OLIVEIRA; BARROS, 2008; LIMA; LIMA-FILHO, 2009).

As categorias 9, 12, 13 e 14 situações de lazer; ingestão de bebidas alcoólicas e tabaco; prática de esportes; tempo de lazer - foram vinculadas para a análise e discussão dos dados aportados. Lima e Lima-Filho (2009) afirmam que a ocupação do professor vincula-se a redução do lazer e da vida social. Isto pode desencadear transtornos na vida destes trabalhadores, podendo gerar sofrimento psíquico. Apesar disto, as descrições 
unânimes dos sujeitos desta pesquisa indicam que os professores universitários dispõem de momentos variados de lazer. Este dado é extremamente importante, visto que o lazer é um dos aspectos estruturantes da saúde mental. O tempo dedicado à realização destas atividades variou entre os sujeitos, porém geralmente acontecem em fins de semana.

Ainda do estilo de vida dos participantes, o Sujeito 4 é o único fumante da amostra e a ingestão de bebidas alcoólicas ocorre apenas socialmente. Com relação às atividades físicas, a maioria dos sujeitos costuma fazer caminhadas. Além desta, foram apontadas outras atividades como natação, corridas, pilates, yoga e aeróbica. Estudos de Bachion et al. (2005) revelam que o estilo de vida influencia no estresse e no desgaste mental. Servilha e Arbach (2011) consideram que o trabalho dos professores e a qualidade de vida mantém relação entre si. Posto isto, enfatiza-se o papel importante da prática de esportes, atividades físicas e de momentos de lazer para redução das dimensões do sofrimento e para aumentar a qualidade de vida dos profissionais da educação.

\section{CONCLUSÕES}

Esta pesquisa delineou como propósito central analisar o sofrimento psíquico de professores universitários das licenciaturas, buscando destacar aspectos e características que compõem seu ambiente de trabalho. Especificamente, buscou averiguar a concepção que os professores do curso de licenciatura em Pedagogia têm sobre o exercício da docência, identificar aspectos que compõem o ambiente de trabalho dos professores universitários e investigar a saúde física e mental destes profissionais.

Para este fim, foi realizada uma pesquisa de abordagem qualitativa, do tipo estudo de caso, aplicando questionário/entrevista semiestruturados em quatorze professores que ministram aulas em um curso de licenciatura em Pedagogia de uma Instituição de Ensino Superior particular do interior de São Paulo. Para a compreensão da temática contou-se com aportes teóricos da Psicodinâmica do Trabalho e da Psicologia Social, bem como de contribuições relevantes de artigos científicos. Após a leitura minuciosa deste referencial, os dados coletados foram organizados por eixos e categorias para a análise e discussão, respeitando os objetivos propostos por esta pesquisa.

O Eixo I verificou por meio de categorias a concepção que os professores do curso de licenciatura em Pedagogia têm sobre o exercício da docência. Os resultados revelaram que os professores universitários possuem uma perspectiva consciente e 
abrangente da ação docente nas universidades e que isso influi em suas práticas laborais diárias. O Eixo /l ao abordar aspectos e características do ambiente de trabalho dos professores universitários apontou precarização e deterioração do ambiente laboral acadêmico, sendo que os sujeitos demonstraram vivenciar sensações de instabilidade, ameaças, insatisfações, frustrações, sobrecarga e desvalorização no mundo do trabalho. O Eixo III investigou a saúde física e mental dos professores universitários e revelou que a maioria dos participantes concorda que a profissão de docência é capaz de desenvolver sofrimento psíquico. Grande parte da amostra apresenta sintomas e problemas relacionados a estresse, fadiga excessiva, desgaste da voz, nervosismo, inquietações, dores variadas, ansiedade e depressão.

Estes resultados permitem, com prudência, afirmar que $o$ trabalho dos professores universitários possui elementos capazes de desencadear sofrimento psíquico e trazer consequências negativas para a saúde física e mental destes profissionais, pois há evidências de problemas de carga mental e sofrimento no trabalho acadêmico. Para amenização e superação desta situação, aspectos como compreensão, respeito, autonomia, reconhecimento social e flexibilidade são fundamentais. Sem embargo, a sociedade desvaloriza o docente e deprecia este profissional, que muitas vezes, trabalha em condições precárias e sem infraestrutura, tendo que despender esforços em demasia. Esses fatores compõem o sofrimento e refletem na saúde dos professores universitários.

Embora os questionamentos não se esgotem, esta pesquisa espera ter atendido as expectativas pretendidas. Aliás, propõe-se a realização de novas investigações no intuito de agregarem possíveis soluções para o problema que norteou este trabalho.

\section{REFERÊNCIAS}

ARAÚJO, T. M.; SENA, I. P.; VIANA, M. A.; ARAÚJO, E. M. Mal-estar docente: avaliação de condições de trabalho e saúde em uma instituição de ensino superior. Revista Baiana de Saúde Pública, v. 29, n.1, p. 6-21, jan./jun. 2005.

BARDIN, L. Análise de conteúdo. Tradução Luis Antero Reto, Augusto Pinheiro. São Paulo: Edições 70, 2011.

BACHION, M. M.; ABREU, L. O.; GODOY, L. F.; COSTA, E. C. Vulnerabilidade ao estresse entre professores de uma universidade pública. R Enferm, UERJ, Rio de Janeiro, 13:32-7, 2005.

CODO, W.; SAMPAIO, J. J. C. HITOMI, A. H. Indivíduo, trabalho e sofrimento: uma abordagem interdisciplinar. Petrópolis: Vozes, 1993.

CODO, W.; SAMPAIO, J. (Orgs.). Sofrimento Psíquico nas Organizações. Petrópolis: Vozes, 1995.

CODO, W. (Org.). Educação: carinho e trabalho. Universidade de Brasília, 
Laboratório de Psicologia do Trabalho.

Petrópolis: Vozes, 1999.

DEJOURS, C. A loucura do trabalho: estudo de psicopatologia do trabalho. 4. ed. São Paulo: Cortez, 1991.

DEJOURS, C. Subjetividade, trabalho e ação.

Revista Produção, v. 14, n. 3, p. 27-34, set./dez. 2004.

http://dx.doi.org/10.1590/s010365132004000300004

DEJOURS, C.; DESSORS, D.; DESRIAUX, F. Por um trabalho, fator de equilíbrio. Rev. de Adm. Empres, São Paulo, v. 33, n. 3, p. 98104, maio/jun. 1993.

FREIRE, P. Pedagogia da autonomia: saberes necessários à prática educativa. 43. ed. Paz e Terra, 2011.

GARCIA, A. L.; OLIVEIRA, E. R. A.; BARROS, E. B. Qualidade de vida de professores do ensino superior na área da saúde: discurso e prática cotidiana. CogitareEnferm, 13(1), p. 18-24, jan./mar. 2008. http://dx.doi.org/10.5380/ce.v13i1.11945

GUIMARÃES, F. A. L.; MARTINS, M. C. F. Valores e prazer-sofrimento no trabalho: um estudo com profissionais de nível superior.

Estudos de Psicologia, Campinas, 27(2), p.133-145, abr./jun. 2010.

http://dx.doi.org/10.1590/S0103166X2010000200001

GRADELLA, O. J. Sofrimento psíquico e trabalho intelectual do docente universitário. Cadernos de psicologia social do trabalho, Marília, v. 13, n. 1, p. 133-148, 2010.

IWATA, H.; OLIVEIRA, D. D.; IVERS, J. F.; RIBEIRO, S. F. R. Estratégia de Saúde da Família Saúde do Agente Comunitário de Saúde a partir de um Diagnóstico Organizacional. Anais do 19 encontro de serviços-escola de psicologia do estado de São Paulo: o papel da formação em psicologia frente as demandas de saúde pública. São Paulo, ago./set. 2011.

JILOU, V. Capitalismo flexível, trabalho precarizado e sofrimento psíquico de professores universitários. Revista Encontro de Pesquisa em Educação, Uberaba, v. 1, n. 1, p. 187-201, 2013.

LIMA M. F. E. M.; LIMA-FILHO D. O. Condições de trabalho e saúde do/a professor/a universitário/a. Ciências \& Cognição, v. 14, n. 3, p. 62-82, 2009.

MASETTO, M. T. Competência pedagógica do professor universitário. São Paulo: Summus, 2003.

MENDES, L.; CHAVES, C. J. A.; SANTOS, M. C.; NETO, G. A. M. Da arte ao ofício: vivências de sofrimento e significado do trabalho de professor universitário. Rev. Mal-estar e subjetividade, Fortaleza, v. 7, n. 2, p. 527556, set. 2007.

OLIVEIRA, M. M. Como fazer pesquisa qualitativa. 2. ed. Petrópolis: Vozes, 2008.

RIBEIRO, S. F. R.; MARTINS, S. T. F. Sofrimento psíquico do trabalhador da saúde da família na Organização do Trabalho.

Psicologia em estudo, Maringá, v. 16, n. 2, p. 241-250, abr./jun. 2011.

SERVILHA, E. A. M.; ARBACH, M. P. Queixas de saúde em professores universitários e sua relação com fatores de risco presentes na organização do trabalho. DistúrbComum, São Paulo, 23(2), p. 181-191, ago. 2011.

SUDA, E. Y.; COELHO, A. T.; BERTACl, A. C.; SANTOS, B. B. Relação entre nível geral de saúde, dor musculoesquelética e síndrome de burnout em professores universitários.

Fisioterapia e Pesquisa, São Paulo, v. 18, n. 3, p. 270-274, jul./set. 2011. 
TARDIF, M. Saberes docentes e formação

profissional. 11. ed. Petrópolis: Vozes, 2010.

Vedovato, T. G.; MONTEIRO, M. I. Perfil sociodemográfico e condições de saúde e trabalho dos professores de nove escolas estaduais paulistas. Rev. Esc. Enferm, v. 42, n. 2, p. 290-297, 2008.

http://dx.doi.org/10.1590/s008062342008000200012

XAVIER, M. Trabalho e sonhos: desejos e pesadelos de professores e trabalhadores da saúde na era do capitalismo organizacional. Cadernos de Psicologia Social do Trabalho, Universidade Autônoma de Barcelona (Espanha), v. 14, n. 1, p. 93-110, 2011.

Recebido para publicação em 11/08/2014 Aceito em 26/08/2014 